\title{
Experimentação do tempo e estilo de vida em contexto de trabalho imaterial
}

\author{
An investigation of time and lifestyles within an immaterial labor context \\ Carmem Ligia lochins Grisci ${ }^{1}$ \\ Jonas Cardoso ${ }^{2}$
}

\section{Resumo}

Este artigo buscou responder, em contexto de trabalho imaterial, que estilo de vida decorre do uso do tempo permeado pelas tecnologias da informação e comunicação. O estudo qualitativo contou com a participação de 18 docentes horistas de instituições de ensino superior privadas. A coleta de dados se deu por meio de entrevista individual semiestruturada, com foco no uso das tecnologias da informação e comunicação e no exercício do trabalho imaterial, considerando o tempo de trabalho e de não trabalho. A análise de conteúdo partiu dos dados coletados. Os resultados, em consonância com a literatura - em especial, Bauman (2008b), Deleuze (1998), Giddens (2002), Gorz (2005) e Lazzarato e Negri (2001) -apontaram que, em contexto de trabalho imaterial, o estilo de vida é instrumentalizado pelo modo de trabalhar e pelo uso das tecnologias de informação e comunicação. Ele se configura como uma imposição aos sujeitos que o toma na perspectiva de uma estratégia existencial consumista. Mesmo contratado por tempo fracionado em horas, o trabalho dos docentes horistas exige-lhes disponibilidade e mobilização total para o desempenho das atividades laborais, requerendo dedicação em tempo integral. Os estilos de trabalho produzem estilo de vida e sugerem que a vida está sendo convertida em trabalho nos dias de hoje, tanto pela intensificação do trabalho, como pelo prolongamento da jornada.

Palavras-chave: Tempo de trabalho e de não trabalho. Estilo de vida. Trabalho imaterial. Tecnologias da informação e comunicação.

\section{Abstract}

The present study sought to establish the lifestyles that arise from the use of time that permeates information and communication technologies, within the context of immaterial labor. This qualitative study included 18 professors from private higher education institutions hourly paid. Data were collected through individual semi-structured interviews focused on the use of information and communication technologies, and in immaterial labor, considering working and nonworking time. The results were in accordance with the literature, particularly Gorz (2005), Lazzarato and Negri (2001), Bauman (2008b), Giddens (2002) and Deleuze (1998). They showed that, in the context of immaterial labor, lifestyles are the result of different ways of working and the use of information and communication technologies. They are imposed on individuals who take them as a perspective of an existential consumer strategy. Though under contract for a given number of hours, the work of the hourly paid professors requires their full availability and mobilization to the

Artigo recebido em 8 de janeiro de 2014 e aceito para avaliação em 2 de outubro de 2014.

\section{DOI: http://dx.doi.org/10.1590/1679-395114752}

Doutora em psicologia pela Pontifícia Universidade Católica do Rio Grande do Sul; Professora associada da Escola de Administração da Universidade Federal do Rio Grande do Sul; Pesquisadora CNPq 1D. Endereço: Escola de Administração/UFRGS, Av. Washington Luiz, 855 - sala 424, Centro Histórico, CEP 90014-460, Porto Alegre-RS, Brasil. E-mail: cligrisci@ea.ufrgs.br

2 Doutor em administração pela Universidade Federal do Rio Grande do Sul; Professor adjunto da Fundação Universidade Federal de Rondônia; Tutor PET Economia/UNIR. Endereço: Departamento Acadêmico de Ciências Econômicas da UNIR, Br 364, Km 4,5, sentido Acre, Área Rural, CEP 76801-000, Porto Velho - Rondônia, Brasil. E-mail: jonas@unir.br 
performance of their work activities, requiring full-time commitment. Working styles produce lifestyles, suggesting that modern-day life is becoming work, both due to the greater intensity of work itself and longer working days.

Keywords: Working and nonworking time. Lifestyles. Immaterial labor. Information and communication technologies.

\section{Introdução}

Este artigo parte do pressuposto de que a massificação e a intensificação do uso das tecnologias da informação e comunicação, em contexto de trabalho imaterial, acarretam transformações no estilo de vida ou modos de existência dos trabalhadores (AUBERT, 2011; BAUMAN, 1999; 2001; 2008a; CASTELLS, 2005; DELEUZE, 1998; GIDDENS, 2002; GORZ, 2005; PELBART, 2003). Essas transformações estão relacionadas com as mudanças no modelo de produção baseado no trabalho material, o qual passa a incorporar, em maior grau, o trabalho imaterial (GORZ, 2005).

A informatização é uma etapa importante na realização do trabalho imaterial compreendido como produtivo e rentável aos olhos da gestão. Ela facilita o controle e o uso intensivo das capacidades inerentes às atividades laborais. Exemplo disso é o uso de aparelhos de telefonia móvel, que se torna uma forma de controlar o trabalhador onde quer que esteja (CASTELLS, FERNÁNDEZ-ARDĖVOL, QIU et al., 2007). Se o tempo de não trabalho era bem delineado sem a tecnologia móvel, agora torna-se difícil separá-lo do tempo dedicado ao trabalho (POCHMANN, 2011). Pode-se afirmar que há uma intensificação da produção a partir da valorização do trabalho imaterial pela gestão, uma vez que o trabalhador utiliza seu potencial criativo para a organização que o emprega (DAL ROSSO, 2006).

A tensão em torno das tarefas e dos compromissos do trabalho se tornou companheira do trabalhador em qualquer lugar e a qualquer hora, afetando seu estilo de vida. Por estilo de vida, cabe adiantar, entende-se "a invenção de uma possibilidade de vida, de um modo de existência” (DELEUZE, 1998, p. 126). Esse estilo de vida se apresenta como um conjunto de "práticas rotinizadas, [de] rotinas incorporadas em hábitos de vestir, comer, [de] modos de agir e [de] lugares preferidos de encontrar os outros" (GIDDENS, 2002, p. 80). Nessa perspectiva, é possível afirmar a indissociação entre trabalho e estilo de vida.

Embora tal afirmação corresponda ao trabalho como um todo na sociedade atual, ela guarda especificidades no que se refere ao uso das tecnologias da informação e comunicação. O trabalho imaterial, compreendido como algo inerente ao trabalhador, também guarda peculiaridades relativas a essas tecnologias. Considerando o exercício do trabalho imaterial, o trabalho de docentes horistas de instituições de ensino superior privado, em especial, mostra-se pertinente à questão da experimentação do tempo. Os docentes configuram uma das categorias de trabalhadores cujos modos de trabalhar condizem com a noção de trabalho imaterial. As instituições de ensino superior privadas contemplam e requisitam as características do trabalho imaterial que mobiliza aspectos pessoais dos docentes em favor do trabalho, alcançando a vida em sua totalidade. A utilização das tecnologias da informação e comunicação faz parte da rotina desses docentes. Estes as utilizam em sala de aula e fora dela para atender às demandas dos alunos e da própria instituição, podendo contemplar seu tempo de trabalho e de não trabalho.

Diante disso, toma-se como pertinente indagar: em contexto de trabalho imaterial, que estilo de vida decorrem do uso do tempo permeado pelas tecnologias da informação e comunicação? Buscando responder a tal questão, propôs-se o objetivo de descrever e analisar o cotidiano de docentes em relação ao uso da tecnologia da informação e comunicação, considerando o local e os horário oficial e não-oficial de trabalho, bem como as relações que se estabelecem entre trabalho imaterial, tempo e estilo de vida.

$\mathrm{O}$ artigo está dividido em quatro seções: a primeira engloba a discussão teórica, a segunda apresenta os procedimentos metodológicos adotados para o estudo e a terceira apresenta os resultados e análise, seguindose as considerações finais. 


\title{
Referencial Teórico
}

A compreensão de Deleuze (1998, p. 125-126) a respeito de estilos de vida é frutífera para os desdobramentos relativos ao uso da tecnologia da informação e comunicação no tempo de trabalho e de não trabalho.

\begin{abstract}
A constituição dos modos de existência ou dos estilos de vida não é somente estética, é o que Foucault chama de ética, por oposição à moral. A diferença é essa: a moral se apresenta como um conjunto de regras coercitivas de um tipo especial, que consiste em julgar ações e intenções referindo-as a valores transcendentes (é certo, é errado...); a ética é um conjunto de regras facultativas que avaliam o que fazemos, o que dizemos, em função do modo de existência que isso implica. Dizemos isto, fazemos aquilo: que modo de existência isso implica? [...] Às vezes basta um gesto ou uma palavra. São os estilos de vida, sempre implicados, que nos constituem de um jeito ou de outro. [...] Mas se há nisso uma ética, há também uma estética. O estilo, num grande escritor, é sempre também um estilo de vida, de nenhum modo pessoal, mas a invenção de uma possibilidade de vida, de um modo de existência.
\end{abstract}

A essa compreensão aproxima-se Bauman (2008b, p. 47) ao dizer que "a ideia do 'tempo da necessidade' foi substituída pelo conceito de 'tempo de possibilidade', tempo aleatório, aberto em qualquer momento ao imprevisível irromper do novo". O uso das tecnologias da informação e comunicação "proporciona comunicação imediata e ampla acessibilidade, além de disponibilizar ferramentas sofisticadas que servem para a produção do trabalho imaterial, móvel e circulante" (FREZZA, GRISCI e KESSLER, 2009, p. 15). O celular e a internet, por exemplo, podem ser utilizados na solução de problemas imprevisíveis e na diminuição do tempo necessário para executar tarefas tanto no local de trabalho como fora dele. Os docentes horistas das instituições de ensino superior privadas fazem parte desse universo de trabalhadores e poderão dizer algo quanto aos estilos de vida contemporâneos.

Com o avanço da informatização, surge o estímulo à disponibilidade ininterrupta para o trabalho, pois o trabalhador perde a capacidade de perceber os limites entre tempo dedicado ao trabalho e tempo de não trabalho (ALVES, 2009). Essa disponibilidade também se faz notar em decorrência do aumento do controle sobre prazos e metas, os quais estão bem delineados para as organizações por meio da informatização, e adquirem caráter de urgência (AUBERT, 2011). Além disso, "as tecnologias informacionais são mediadores fundamentais da disponibilidade total; elas permitem a eliminação das barreiras espaço/temporais para o trabalho e seu acúmulo no tempo" (ALVES, 2009, p. 154). O trabalhador passa a realizar tarefas fora de seu local de trabalho por transbordamento, ou seja, "preocupações profissionais $24 / 24 \mathrm{~h}$ e interação com diferentes formas de solicitações, como e-mail, celular, fax etc.” (ROSENFIELD e ALVES, 2011, p. 11).

A velocidade tornou-se o novo modo de experimentar o tempo, o qual é apropriado pelas organizações capitalistas em busca do lucro (AUBERT, 2011). O estilo de vida dos trabalhadores, por sua vez, ficou mais dependente das organizações capitalistas, que retêm as vagas de emprego àqueles que aceitam o contrato de dedicação sem questionamentos, aceitando metas e prazos como missão principal em suas vidas e procurando se destacar cada vez mais, para ir mais longe, mais rápido, tornando-se mais forte, trabalhando incansavelmente para ser o melhor (AUBERT, 2011). O trabalhador se torna então uma empresa que tem capital humano a oferecer, o qual deve render conforme se especializa e consome o que as organizações solicitam (GAULEJAC, 2007). Assim, "é mister que o trabalhador se identifique pessoalmente, que se mobilize subjetivamente, que lance mão de suas capacidades psíquicas e relacionais para bem executar seu trabalho" (ROSENFIELD e ALVES, 2011, p. 2). Com seu estilo de vida sendo estabelecido a partir dos ditames do capital, o trabalhador experimenta o tempo conforme as necessidades de se manter vendável (BAUMAN, 2010). 
As organizações esperam que seus subordinados sejam fortes, dinâmicos, competentes, disponíveis para enfrentar os riscos inerentes às metas cada vez mais ousadas. Assim avança o processo de fluidez social, resultado da precarização do mercado de trabalho. Os trabalhadores são avaliados por sua mobilização e "identidade flexível, polivalente, que varia em função das imprevisibilidades da carreira" (GAULEJAC, 2007, p. 244), em detrimento da profissão definida e da experiência acumulada (AUBERT, 2011), o que implica produção de estilo de vida que se vê nas práticas rotinizadas e instrumentalizadas, condizente com uma experimentação do tempo a favor do capital (BAUMAN, 2010; GIDDENS, 2002).

Embora alguns países mostrem uma tendência à diminuição da jornada de trabalho padrão, a complexidade e a imprevisibilidade relativas às horas direcionadas ao trabalho têm se mostrado crescentes devido às demandas em atividades organizacionais mais intensas e prolongadas. Delas decorre forte pressão por dedicação ao trabalho por mais tempo, de forma a estar disponível às demandas organizacionais, independentemente de outras instâncias da vida como as relações familiares ou o lazer (GAULEJAC, 2007; MALENFANT e FOUCHER, 2006; OLTRAMARI, GRISCI e WEBER, 2011; WEBER e GRISCI, 2011; WEBSTER, 2004). Mais do que a realização de tarefas, a organização produtiva baseada no assalariamento define o ritmo para a organização da vida diária, um ritmo que ao não levar em conta o ritmo fora do trabalho, impõe-se a ele (MALENFANT e FOUCHER, 2006).

A chamada extensificação do trabalho (RUBERY, WARD, GRIMSHAW et al., 2005) - o aumento do tempo dedicado ao trabalho e de sua crescente imprevisibilidade - tem claras consequências para quem trabalha além do local de trabalho. O resultado é a intensificação da invasão do tempo privado por compromissos com o trabalho, comprometendo a vida. Como bem exemplifica Bauman (2010), na manutenção de um elevado padrão de vida, há um preço a ser pago: a contínua dedicação ao mundo do trabalho, alterando o tempo dedicado ao ambiente profissional e moldando o estilo de vida dos trabalhadores. Percebe-se, assim, um círculo vicioso no qual as necessidades criadas para manutenção do estilo de vida levam ao consumismo, que por sua vez levam à procura por aumento da renda. Isso não reduz, entretanto, a noção de estilo de vida à área do consumo.

Não estando alijado da arena das escolhas plurais, o trabalho "constitui um elemento básico das orientações de estilo de vida na extremamente complexa divisão moderna do trabalho" (GIDDENS, 2002, p. 80). Os trabalhadores devem entrar no processo de produção com toda a bagagem cultural adquirida nos jogos, esportes de equipe, nas lutas, atividades musicais, teatrais etc. (GORZ, 2005). Ao ser utilizada em prol da inclusão no trabalho e de sua rentabilização, essa bagagem cultural reflete o encorajamento "de um estilo de vida e uma estratégia existencial consumistas [...] Uma escolha viável e, portanto, plausível - e uma condição de afiliação" (BAUMAN, 2008a, p. 71). É o saber do trabalhador que a organização põe para trabalhar, e explora.

A organização vai ao mercado e adquire "capital humano" pronto, fruto do esforço do trabalhador para se qualificar e se atualizar para servir ao capital, um recurso gratuito, como assegura Gorz (2005), que depois de adquirido é canalizado para a produção. Assim, "a esfera da produção capitalista de uma vez por todas estendeu-se da organização do 'tempo de trabalho' à organização do 'tempo de vida" (LAZZARATO e NEGRI, 2001, p. 74).

A noção de trabalho imaterial traz implicações à concepção do tempo. $\mathrm{O}$ abandono dos rígidos padrões espaço-temporais do modelo de produção fordista relaciona-se com as transformações ocorridas nas relações de trabalho nos últimos 30 anos do século XX, associado principalmente com o crescimento do setor de serviços e a informatização nos processos produtivos e comunicacionais.

O trabalho imaterial é responsável pela produção do conteúdo informativo e cultural do produto. Essa concepção modifica a forma de trabalho na indústria e no setor de serviços, pois as atividades devem estar em consonância com a informação e comunicação intra e extra organização (LAZZARATO e NEGRI, 2001). Ao tomar-se as instituições de ensino superior privadas onde impera a lógica "o cliente é o rei", aproxima-se das discussões a indicarem que "do trabalho imaterial resultam, além de produtos materiais, 
produtos intangíveis como sentimentos de confiança, segurança e conforto aos clientes numa nova relação produção-consumo" (GRISCI, 2008, p. 4).

Mesmo nas atividades mais simples, o trabalhador recebe treinamentos que visam prepará-lo para atender bem ao cliente e estar sempre à disposição da organização para tarefas eventuais. Encontram-se aí envolvidas dimensões subjetivas compreendidas como indispensáveis à preferência dos clientes e à rentabilização e permanência das empresas no mercado (GRISCI, 2008; MANSANO, 2009). Características como autocontrole, disponibilidade, sociabilidade, criatividade e bom humor, antes pertencentes apenas ao trabalhador na produção fordista, agora são consideradas competências relacionais e o trabalhador vê-se obrigado à disponibilizá-las intensivamente ao projeto organizacional (BOLTANSKI e CHIAPELLO, 2009; GAULEJAC, 2007; PELBART, 2003).

Os padrões espaços-temporais, antes bem definidos e descritos na produção fordista e amparados numa burocracia visível, tornam-se mais implícitos no contexto do trabalho imaterial, que como tal conduz a novas descobertas e possibilidades ancoradas nas tecnologias da informação e comunicação (LAZZARATO e NEGRI, 2001). Os controles tornam-se mais sutis e eficazes, alocando o processo burocrático numa contradição. As relações de trabalho parecem mais afeitas à liberdade de tempo e espaço, mas imprimem um ritmo intenso baseado em metas de produção (GRISCI, 2008; GRISCI, SCALCO e KRUTER, 2011; LAZZARATO e NEGRI, 2001). O processo de produção deve ser conhecido e entendido por todos os trabalhadores que, ao controlarem algumas de suas partes, devem aperfeiçoá-lo por meio de seus conhecimentos (LAZZARATO e NEGRI, 2001). O termo colonização do espaço e do tempo dos trabalhadores, utilizado por Gaulejac (2007) em relação ao novo modo de produção, complementa-se com a explicação de Lazzarato e Negri (2001) de que, na contemporaneidade, o trabalho imaterial molda um novo trabalhador, o qual não tem domínio sobre o tempo, está fadado a dedicar o seu tempo tanto de trabalho como o que seria de não trabalho, ao capital.

\section{Procedimento Metodológico}

Para atingir os objetivos pretendidos, optou-se pela pesquisa qualitativa descritiva (HAGUETE, 1995) e se buscou ter uma visão geral sobre o modo como os sujeitos entendem o tema proposto. Apesar de consistente, a literatura sobre o tema se mostra exígua quanto à especificidade do trabalho docente. Nesse sentido, por conveniência, optou-se neste estudo pela aproximação de uma realidade empírica condizente com a noção de trabalho imaterial e marcada pela familiaridade com as tecnologias da informação e comunicação. Nesse contexto, foi possível acessar, como sujeitos da pesquisa, 18 docentes horistas de sete instituições de ensino superior privadas da cidade de Porto Velho, no estado de Rondônia. Eles integram a área de educação e cultura, um dos setores cujo exercício profissional demanda inteligência, afetividade e capacidade de relacionamento (DAL ROSSO, 2008).

Foi levado em conta, também, o ambiente organizacional competitivo, que exige constante inovação e resultados para se manter no mercado. Nesse ambiente, os docentes têm de demonstrar suas habilidades e envolvimento efetivo para a aprendizagem dos alunos, Para isso, contam com a experiência adquirida ao longo da vida, mantendo-se atualizados quanto às tecnologias da informação e comunicação utilizadas no desempenho de suas funções dentro e fora do local de trabalho.

Os dados foram coletados por meio de 18 entrevistas individuais semiestruturadas. Realizadas nos locais de trabalho dos entrevistados, essas entrevistas tiveram duração média superior a 30 minutos, sendo gravadas com a autorização dos entrevistados e, depois, transcritas. O contato inicial com os entrevistados foi feito por e-mail, conhecido a partir de um levantamento nas instituições de ensino superior privadas, via internet, para coleta prévia dos endereços eletrônicos dos docentes dessas instituições. Em seguida, foram enviados 47 convites por e-mail, independente de instituição, gênero ou idade. Do total de convites enviados, 34 docentes responderam, dos quais 23 aceitaram o convite, enquanto os demais agradeceram o contato, mas alegaram compromissos agendados previamente. Dos 23 docentes que aceitaram ser entrevistados, foi possível efetuar 
18 encontros. Os cinco restantes não foram realizados devido a desencontro de horários e compromissos que foram aparecendo de última hora para tais docentes.

O segundo contato foi feito a partir dos aceites recebidos, sendo marcados em seguida o local e o horário que o docente disponibilizava. Do total de 18 entrevistados, na oitava entrevista, já era possível determinar um padrão nas respostas. Mesmo assim, optou-se por entrevistar mais 10, para confirmação e melhor qualificação do trabalho de campo.

Para a coleta de dados, foi considerado também, conforme Minayo (2001), que é preciso compreender não apenas as falas do entrevistado. Foi levada em conta também a necessidade de se perceber e registrar todos os sinais que permitam um maior entendimento do objeto de estudo e do sujeito da pesquisa em determinado tempo e espaço. Nesse sentido, a relação dos entrevistados com seus aparelhos telefônicos no momento da entrevista foi vista como uma possível reprodução do que acontece no cotidiano desses profissionais, Por isso, essa relação foi igualmente considerada conteúdo de análise a ser interpretado à luz da teoria.

A análise dos dados tomou as categorias prévias do estudo - trabalho imaterial, tecnologias da informação e comunicação e estilo de vida, considerando o tempo de trabalho e o de não trabalho. Para a delimitação e visualização das categorias de cunho coletivo, emergentes do conjunto das entrevistas, seguiu-se, sequencialmente, as orientações de Minayo (2001): a) organizar o material, decompondo-o em partes; b) distribuir as partes em categorias; c) descrever o resultado da categorização; d) fazer inferências dos resultados a partir do suporte teórico adotado. Tais categorias são: a) o cotidiano dos docentes em relação ao uso das tecnologias da informação e comunicação em local e horário oficiais de trabalho e (além dos locais e horários oficiais de trabalho) b) as relações estabelecidas entre trabalho imaterial, tempo e produção de modos de viver ou estilo de vida. As falas que as compõem, são aquelas que melhor exemplificaram uma ideia compartilhada por vários entrevistados, conforme se verá na seção a seguir.

\section{Resultados e Análise}

Segundo o censo da educação superior (BRASIL, 2012), a cidade de Porto Velho tem 10 instituições de ensino superior privadas; todas, faculdades que oferecem cerca de 70 cursos de graduação. A existência de poucos doutores nas faculdades ocorre por três motivos principais: i) há grande dificuldade de achar esses profissionais com tamanha qualificação na região; ii) os doutores estão, em sua maioria, na Universidade Federal de Rondônia (UNIR) e; iii) o Ministério da Educação e Cultura não exige a contratação de doutores para faculdades. Dessa forma, a pesquisa e a extensão são atividades de pouca expressão nessas instituições, que se limitam, além de oferecer cursos de graduação, a oferecer curso de pós-graduação lato sensu. Os docentes contratados são geralmente mestres ou especialistas, que se limitam a atividade de ensino e orientação de trabalhos de conclusão de curso (TCC).

Os sujeitos da pesquisa têm as seguintes características gerais: 11 são do sexo masculino, e sete do sexo feminino. Quanto à escolaridade, 12 são mestres, cinco têm pós-graduação lato sensu e um estava cursando mestrado. As idades variam de 24 a 57 anos, sendo dois com idade entre 20 e 29 anos, 11 na faixa de 30 a 39 anos, três na faixa de 40 a 49 anos e dois com idade entre 50 e 59 anos. Quanto ao estado civil, três são solteiros, dois são divorciados e os demais são casados. Outras informações: todos os entrevistados trabalham os três turnos nos dias da semana: manhã, tarde e noite. Apenas cinco docentes cumpriam carga horária menor que 20 horas (D3, D8, D11, D13 e D14) nas instituições de ensino superior privadas. A maioria dos entrevistados cumpria acima de 20 horas de sala de aula, com quatro turmas por docente. Apenas seis dos entrevistados não têm filhos (D3, D8, D9, D13, D16 e D17), nove têm filhos com idade entre seis meses e 10 anos (D2, D4, D5, D6, D11, D12, D14, D15 e D18) e os demais têm filhos acima de 10 anos (D1, D7, e D10). As características pessoais dos docentes não se mostraram distintivas de seu estilo de vida ou modos de existência. 
As entrevistas foram realizadas tanto nas instituições de ensino como em repartições públicas, sempre focando o entrevistado como docente quanto às categorias estabelecidas no roteiro. O que se pode abstrair a partir disso é que muitos docentes utilizavam seu tempo de trabalho no setor público para resolver assuntos relacionados com o seu trabalho nas instituições de ensino superior privadas, numa clara dificuldade para estabelecer delimitações relativas ao tempo. Todos os docentes entrevistados possuem mais de um emprego, todos lecionam à noite e trabalham, na sua maioria, no setor público durante o dia. Os docentes trabalham como horistas, não havendo impedimento quanto à ocupação em outro emprego. Em termos de comparação, pode-se dizer que o perfil dos docentes deste estudo está condizente com a categoria profissional, pois quase $80 \%$ dos docentes de instituições de ensino superior privadas são horistas ou trabalham em tempo parcial (BRASIL, 2012).

A duração das entrevistas mostrou-se intrinsecamente relacionada com o atendimento das respostas do roteiro elaborado. Muitos entrevistados foram lacônicos, limitando-se a responder de forma breve às perguntas formuladas. O tempo exíguo para a realização da entrevista foi justificado pelo acúmulo de compromissos de atividades típicas de fim de semestre - preparação e correção de provas, lançamento de notas e elaboração de relatórios. Compreende-se esse comportamento, também, pelo fato das entrevistas terem sido realizadas em seus locais de trabalho, ambientes percebidos como carregados. Muitas entrevistas tiveram que ser interrompidas para que os entrevistados atendessem chamadas telefônicas ou pessoas. Todos os docentes tinham seus celulares ao alcance das mãos. Um deles portava três telefones celulares, que segundo ele, era para atender as demandas diferenciadas, dado que ele usava vários chips de empresas telefônicas variadas (D15). O uso dos telefones celulares durante as entrevistas fez com que o entrevistador fosse deslocado para uma posição de coadjuvante em relação aos equipamentos. Tal modo de interação mostrou os docentes prisioneiros de seus equipamentos tecnológicos, permitindo inferir alteração na noção de presença e, também, tensão no estilo de vida condizente com a ideia de prontidão dispensada às demandas supostamente urgentes que tais equipamentos pudessem anunciar.

\section{Cotidiano dos Docentes em Relação ao Uso da Tecnologia da Informação em Local e Horário Oficiais de Trabalho}

O uso das tecnologias da informação e comunicação nas organizações é uma realidade nas instituições de ensino superior privadas de Porto Velho - Rondônia não é diferente. Isso ocorre mesmo com essas instituições estando geograficamente situadas às margens dos grandes centros produtivos, onde se pressupõe sejam mais claramente evidenciadas a intensificação do trabalho humano e as alterações do estilo de vida dela decorrentes (BAUMAN, 2008a; DAL ROSSO, 2008). Para o bom funcionamento do negócio, há necessidade de investimentos em equipamentos atualizados que forneçam subsídios para o crescimento e/ou manutenção do lucro. As salas de aula, principal área de trabalho dos docentes deste estudo, não apresentam mais apenas uma lousa e um pincel, comportam também tecnologias que possibilitam novas dinâmicas de ensino.

O docente, por sua vez, deve estar preparado para utilizar tais tecnologias, pois, caso contrário, não será considerado apto para atender, de pronto, às exigências da organização que lhe emprega, de mostrar comprometimento com o negócio (BAUMAN, 2010; GAULEJAC, 2007). Assim, ao contar que a faculdade disponibiliza wi-fi no prédio inteiro, e que "já entra com sua senha, já faz a chamada online, passa e lança a matéria do dia", D12 ressalta que "não deixa nada acumular pra última hora". A descrição acrítica de seu modo de trabalhar a impede de problematizar o próprio estado de prontidão em relação a um tempo da urgência observado na destreza com que maneja os aparatos tecnológicos de que dispõe. Identificada com o trabalho, ela possibilita ver que o tempo da urgência se reflete na velocidade das ações ininterruptas, neste instante, sem demora.

Foi visualizado um padrão quanto ao uso dos equipamentos de tecnologia pelos docentes. Embora as instituições de ensino superior privadas, em geral, disponibilizem os equipamentos necessários para o atendimento das demandas em sala de aula, os docentes preferem utilizar seus próprios equipamentos. "Para 
realizar minhas atividades na faculdade, eu uso meu modem, notebook e Datashow. Na verdade, eu uso tudo meu. Só uso a energia da faculdade [risos]. Porque uso minha extensão, minha caixa de som [...] não dependo dos recursos da instituição" (D10). "Eu levo meu notebook, pois a faculdade não disponibiliza o equipamento. Só em últimos casos. Você tem que ter o seu. Ela disponibiliza o datashow” (D12).

A justificativa para o uso de equipamento próprio está relacionada com a comodidade de poder contar com o equipamento à sua disposição a qualquer tempo e em qualquer lugar; seja no tempo de trabalho ou de não trabalho. Assim, fica demonstrado que o trabalhador, conforme afirma Gaulejac (2007), consome o que as organizações solicitam; ou seja, adquirem equipamentos próprios para aumentarem a velocidade e a disponibilidade apropriadas para (e pela) organização capitalista. A docente D9 diz que "hoje em dia, se você chega em sala de aula para dar aula com uma fichinha, você cai em descrédito dos alunos. Tem que estar antenada, estar conectada com o que tem de informação nova e de equipamento novo". Tem que garantir, desse modo, uma imagem distante da obsolescência e de possível descartabilidade.

O uso de celulares e internet, para Castells, Fernández-Ardèvol, Qiu et al. (2007), facilita a obtenção de informações para a tomada de decisão, o que se mostra útil no que tange à acessibilidade e resposta rápida. A utilização dessas tecnologias da informação e comunicação pode tornar o docente refém da necessidade constante de informação e de atualização. "E-mail, eu consulto em todos os lugares. Geralmente, eu consulto e-mail uma ou duas vezes por dia, quando chego no trabalho e na hora do almoço" (D1). Todos os entrevistados têm mais de um e-mail, e costumam consultá-los conjuntamente. Como ressalta D1: "Eu me considero uma pessoa atualizada. Tenho que me atualizar por causa da minha área." Notou-se como padrão a consulta de e-mails nas mais diversas ocasiões e lugares, e de modo frequente. "[...] recebo informações da instituição, que está sempre mandando uma coisa diferente. Por exemplo, hoje eu não acessei o e-mail em determinado período e tinha uma informação que eu precisava hoje de manhã. Então, naquele tempo que eu fiquei sem acessar o e-mail, um outro colega já tinha a informação que eu não tinha” (D18).

Na lógica vigente de que é necessário chegar primeiro e ser o melhor, estar impedido de corresponder a esse padrão gera penalidades ao docente. O impedimento é imediatamente percebido como indicador de desatualização e de desvantagem em relação aos demais colegas. O imperativo da atualização está associado à valorização pessoal necessária para não se tornar um "refugo humano", expressão que Bauman (1999), criticamente, identifica associada aos trabalhadores que estão à margem do mercado de trabalho por não apresentarem a qualificação necessária para serem "comprados" e utilizados nas ocupações disponíveis. Em consequência disso, os docentes acabam investindo seu próprio dinheiro e tempo de não trabalho (supostamente livre) para: a) conhecer a tecnologia disponível no mercado; b) pesquisar os melhores preços e condições de pagamento e c) comprar seus próprios equipamentos.

"Eu comprei meu notebook exatamente por causa de meu trabalho" (D2). O tempo disponibilizado para essas atividades, contudo, não se mostrou computado como tempo de trabalho por parte dos docentes. Não lhes ocorre tomar o tempo comprometido para tanto, como tempo expandido de trabalho. Isso ilustra, em harmonia com a literatura (GAULEJAC, 2007; GORZ, 2005), a colonização do tempo da vida em prol das exigências relativas ao exercício do trabalho imaterial. Além do que, os bens de consumo adquiridos tendem a ser bens que sirvam como meio de promoção, meio de manutenção do emprego, de busca por valoração no mercado (BAUMAN, 2008a).

Diante da constatação inócua em termos de resistência, por não colocar em questão a organização do trabalho - "no trabalho o tempo parece muito curto para resolver tantas coisas" (D4) -, o uso da tecnologia da informação e comunicação em sala de aula passa a ser rotinizado para melhorar o desempenho didático e proporcionar outras formas de interação com os alunos. Dois docentes (D7 e D11) relataram que utilizam os equipamentos apenas para aulas que necessitam do uso dos mesmos. Como relata D7, "em sala de aula, eu prefiro até dar a aula sem uso da tecnologia, a não ser para colocar uma imagem, um filme; algo para deixar a aula mais bonita, mais criativa". Embora ela tente ser seletiva no uso das tecnologias da informação e comunicação em sala de aula, há que se destacar a busca constante por formas de atender às demandas dos alunos e da instituição. D7 demonstrou, no transcorrer da entrevista, um alto grau de solicitude quanto à rapidez em responder e-mail de alunos, colegas e direção. Desse modo, atestou sua disponibilidade e 
empenho para, em consonância com o projeto organizacional, fazer girar rapidamente a informação para atender prazos e metas.

Inserido em ambiente que requer soluções e respostas imediatas, o docente se vê, num primeiro momento, iludido com a tecnologia da informação e comunicação embarcada em seu notebook e tablet. D3 é clara em relação a isso: "facilita em tudo. Eu sempre digo que não movo minha vida sem ela [tecnologia], principalmente, em relação ao uso do material. Tudo tem no computador [...] tinha que deixar lá no xerox. Os alunos tinham que ir lá; agora, não. Já envio tudo via e-mail". Mas, adverte: "parece tão simples, mas é preciso pesquisar muito na internet, pois ninguém vai enviar para você” (D3).

As tecnologias da informação e comunicação em sala de aula não se restringem ao uso dos docentes. Os alunos também as utilizam para busca de informação. Segundo os docentes, os alunos trazem para a sala de aula seus notebooks, smartphones ou tablets como complementos para acessar o material fornecido pelo professor. Tornou-se corriqueiro o uso desses equipamentos em sala de aula, concomitantemente com o desenvolvimento do conteúdo pelo docente. Isso propicia convergência e intensificação dos conhecimentos produzidos em outros lugares e em outros tempos, no tempo do aqui e agora compartilhado na duração de uma aula. Embora a situação seja vista com simpatia (D9), no geral, os docentes veem o uso de forma defensiva, dadas as possíveis implicações associadas a essa prática. Tais implicações dizem respeito ao medo de ser visto como alguém que: a) não sendo interessante o suficiente, perde o controle da turma; b) por estar desatualizando, torna-se passível de ser considerado ultrapassado e descartável; c) percebe-se capturado pela lógica do mercado perante si mesmo e os outros. Exemplos: "Um que acessa, os três do lado ficam olhando para a tela daquele. Então, não é só aquele que acessa" (D11); “[...] se a aula não for interessante e o aluno também não tiver comprometimento, ele acaba até sendo mal-educado, porque ele vai ficar ali conectado nas mídias sociais [...] se o professor não tiver uma dinâmica, uma interatividade ..." (D15); "se você passa uma informação errada em sala de aula, pode ser que tenha alguém te corrigindo no mesmo momento, não porque ele saiba mais a matéria, mas tem mais acesso à informação ao mesmo tempo" (D8); "[...] você tem que passar a mão na cabeça. Porque hoje as faculdades deixaram de ser instituições de ensino. São de negócios. Se o aluno reprovar hoje, ele não volta pra instituição. E a faculdade quer de volta para receber a mensalidade" (D12). Entende-se por "passar a mão" a necessidade de atender a solicitações tanto da instituição, que precisa do aluno matriculado para manter seu lucro, como também, atender à "necessidade" do aluno, de ter acesso ao diploma de ensino superior.

Isso é percebido como "um desafio hoje para o docente" (D15). No geral, ponderam que são os alunos que vão avaliá-los e que eles dependem dos alunos para manter seus empregos. É a mesma perspectiva de que "para entrar na sociedade de consumidores e receber um visto de residência permanente, homens e mulheres devem atender às condições de elegibilidade definidas pelos padrões do mercado" (BAUMAN, 2008a, p. 82). Nesse sentido, torna-se constante, por parte dos docentes, a busca por tecnologias informacionais mais atuais, e de conhecimento a respeito das mesmas. Dessa maneira, julgam possível compreender melhor os alunos e atender às solicitações que se apresentam. Há de se considerar, no entanto, que as tecnologias informacionais apenas mediam a disponibilidade total que alcança e exige o tempo da vida (ALVES, 2009; GORZ, 2005; LAZZARATO e NEGRI, 2001).

Cotidiano dos Docentes em Relação ao Uso da Tecnologia da Informação para Além dos Locais e Horários Oficiais de Trabalho

Os docentes consideram que devem estar munidos de tecnologia que facilite sua comunicação com seus alunos e com a instituição além dos locais e horários oficiais de trabalho. Nesse bojo, inclui-se aparelho celular, tablet, notebook e computadores com acesso à internet. $\mathrm{O}$ atendimento extra sala extravasa o tempo propriamente contratado. O tempo se torna uma variável menos importante diante da solicitude com os indivíduos agregados à organização (ALVES, 2009). "Quando recebo e-mails de alunos, respondo rápido. Há muita limitação de tempo" (D13). "Estou na instituição a partir das dezoito, mas acaba que, pela internet, praticamente, o dia todo estou trabalhando, atendendo várias demandas" (D7). Refém das demandas da 
instituição, o docente em questão realiza atividades de trabalho de modo ininterrupto; trabalho aparentemente facilitado pela tecnologia da informação e comunicação. Sem levar em conta o contrato relativo ao tempo de trabalho estabelecido, trabalha por transbordamento (ROSENFIELD e ALVES, 2011).

"As demandas que eu recebo por e-mail tomam um pouquinho de tempo, mas aí eu utilizo o horário de almoço ou chego um pouquinho antes, ou fico um pouquinho depois; a gente consegue conciliar" (D9). Cabe ressaltar que o uso que faz do tempo de não trabalho para trabalhar é descrito no diminutivo - um pouquinho de tempo, um pouquinho antes, um pouquinho depois. A concessão observada apresenta característica inofensiva ao ser narrada. Trata-se, contudo, de algo que principia com a apresentação de um sujeito flexível e conciliador, comprometido em exaltar e valorizar as competências relacionais requeridas no exercício do trabalho imaterial, mas que se desdobra como cilada quando incorporado às práticas rotinizadas do estilo de vida ou modos de existência (DELEUZE, 1998; GIDDENS, 2002). Ao assegurar que "final de semana preservo para o descanso, a não ser que tenha uma demanda muito urgente, que tenha prazo", D7 também denota o uso do tempo de não trabalho.

Cabe lembrar que o uso dos equipamentos informacionais facilita e controla o atendimento de prazos e metas, tornando as demandas sempre urgentes (ALVES, 2009). Os docentes D1, D2, D3, D4, D5, D10, D12, D13 e D16 relataram que utilizam os finais de semana, esporadicamente, para resolver ou pensar o trabalho. Por sua vez, D9 contou: "geralmente, no período de férias, eu utilizo para planejamento de aula. Deixo todas as aulas planejadas no período de férias, inclusive, com material que vai ser utilizado". Os demais afirmaram que procuram reservar o fim de semana para descanso e atividades com a família e igreja. No entanto, suas afirmações nesse sentido não se mostram com tanta clareza no cotidiano vivido. "Procuro colocar o celular no silencioso no final de semana. Até pretendo colocar um chip só pra família, mas, se um aluno ligar, eu atendo" (D7).

Segundo Dal Rosso (2006), a utilização da tecnologia da informação e comunicação, que facilita estar online a qualquer momento, tende a desestruturar o entendimento sobre qual é o tempo de trabalho e o tempo de não trabalho, levando a mudanças na forma de conceber onde começa a atividade profissional e onde começa o descanso, o que pode ser constatado entre os docentes deste estudo. Coincidentemente, os mesmos docentes D1, D2, D3, D4, D5, D10, D12, D13 e D16, disseram que utilizam o sítio eletrônico da faculdade durante o fim de semana para lançar notas e ausências de alunos no sistema. Conforme explicita D5: "também utilizo o site da faculdade ou então de arquivos que eu levo no pendrive, também, para lançar notas e faltas no sistema da instituição em casa."

Muitos trabalhadores passam a ver o emprego como se fosse a própria vida, criando uma simbiose entre vida e ocupação profissional, donde se estabelece uma forte dependência com o trabalho (GAULEJAC, 2007). Cabe lembrar que todos os docentes mantiveram por perto seus celulares no momento da entrevista e nenhum deles desligou o aparelho. Além disso, faziam pausa para verificar a hora no aparelho celular. As chamadas telefônicas que receberam durante a entrevista (D1, D4, D6, D7, D8 e D12) foram atendidas imediatamente. Remete-se, assim, a um contexto em que o uso de tecnologias da informação e comunicação alterou a noção de presença, uma vez que os docentes prestavam mais atenção nos sinais vindos de seus aparatos tecnológicos, adotando-os como parte de si. Isso se fez notar no sentimento de D5 sobre o uso das tecnologias da informação e comunicação em seu cotidiano: "O celular faz parte de mim. Ele fica 24 horas ligado. Durmo ao lado dele".

Quanto ao uso do tempo de não trabalho, esse mesmo docente acrescenta: "depois que eu chego em casa. à noite, eu tomo banho, janto e continuo a trabalhar. O tempo, eu controlo pelo meu cansaço. A hora que eu sinto que não dá mais, eu paro. Quando não dá mais pra aguentar, aí, eu paro" (D5). Em relação a isso é acompanhado por D9, quando este conta que usa "o tempo depois das aulas, das 11 até à meia-noite, corrigindo prova, corrigindo trabalho". Trabalhar até a exaustão ratifica a ideia de trabalho por transbordamento.

Os compromissos se misturam, tornando difícil separar o que é relativo a trabalho e a não trabalho. "Você acha que nem é trabalho porque é tão natural, normal. Mas acaba sendo, né? Tempo é dinheiro, né?" (D2) A 
introjeção da máxima "tempo é dinheiro" remete à ideia defendida por Dal Rosso (2008) sobre a intensificação do trabalho dos produtores para maior lucratividade dos detentores do capital.

A disponibilidade total para o trabalho se potencializa na experimentação do tempo que aproxima trabalho e indivíduo através das tecnologias da informação e comunicação. Todos os docentes entrevistados preparam suas aulas fora do horário de trabalho estabelecido em contrato com as instituições. Essa preparação, juntamente com o atendimento das demandas imprevisíveis dos alunos, colegas e coordenação, acontece em locais e horários diversos do ambiente de trabalho, de modo que podem prescindir de deslocamentos físicos para sua realização.

Diante da valorização do trabalho imaterial como algo produtivo e rentável, torna-se difícil para o docente negar-se a abrir o e-mail do aluno que está a apenas um clique, ou deixar de acessar a informação da instituição que, da mesma maneira, está acessível. Se ele se localiza além dos locais e horários oficiais de trabalho, com a presença das tecnologias da informação e comunicação, tornou-se algo secundário.

\section{Relações que se Estabelecem entre Trabalho Imaterial, Tempo e Produção de Estilo de Vida}

Os achados deste estudo ratificam o entendimento de que o trabalho imaterial é aquele que exige disponibilidade total do sujeito e tem por resultado algo que o torna único, que desperta no consumidor sentimentos de confiabilidade, conforto e segurança, entre outros. O que resulta do trabalho imaterial docente condiz com as formas de comunicação estabelecida com os alunos, numa relação que envolve a vida (GORZ, 2005; LAZZARATO e NEGRI, 2001). Com valor de difícil mensuração, o trabalho imaterial precisa de meios para ser integralizado e efetivamente realizar-se na forma de consumo.

O trabalho imaterial se vê esboçado na fala de D9:

[...] existe uma instantaneidade muito grande. Você precisa estar conectado direto. Então, eu acho que eu não posso esperar o dia de ter aula pra eu dar recado para os alunos ou receber material de alunos. [...] Não é mais uma questão de você optar por utilizar ou optar por não utilizar. É uma questão de necessidade. Ou você está conectado ou você não tá. Porque senão você fica atrasado. Você tem que ter disponíveis [equipamentos tecnológicos], e você tem que saber utilizar pra você dar um feedback melhor para seus alunos. Pra você ter uma aplicabilidade melhor naquilo que você está propiciando. Naquilo que você está propondo fazer.

O excerto da entrevista permite compreender o grau de envolvimento do sujeito com o trabalho. A necessidade de se manter conectado em face da instantaneidade vigente, a impossibilidade de postergação, a opção como uma ausência constatada, a ameaça de ficar para trás e a mobilização subjetiva refletem um modo de existência que é convocado a produzir. As tecnologias da informação e comunicação são de grande importância nesse processo, funcionando como suporte para a disponibilidade total dos docentes e eliminando as barreiras impostas pelo espaço e pelo tempo, como salienta Alves (2009).

A tecnologia é percebida como um apoio a facilitar o trabalho e permitir atender às demandas com rapidez. D7 exemplifica: "pela internet sempre estou atenta e respondo com rapidez, e os alunos elogiam. Eles têm as respostas praticamente no mesmo dia ou na mesma hora. Não só respondo, como resolvo". D7 ainda faz questão de salientar: "meus alunos me elogiam muito de ter as respostas quase que imediatas. Eles sabem que funciona. Se passar um e-mail, eles sabem que vou resolver, e essa rapidez é bastante elogiada." Trabalho e trabalhador não se diferenciam, portanto. O mesmo ocorre em relação ao tempo de trabalho e de não trabalho. Como diz D8, "no geral, estou 24 horas conectado às atividades da docência, principalmente para orientações de alunos. Não é uma exigência da faculdade. Na verdade, isso é meu." E continua: "se o aluno mandar e-mail pra mim no sábado e eu abrir, já respondo no sábado mesmo. Eu gosto de dar este feedback rápido. Tira a ansiedade do aluno." 
Ao menos, duas questões mostram-se imbricadas nas falas dos docentes. Primeira: as tecnologias da informação e comunicação vieram a contribuir para implodir barreiras entre tempo de trabalho e tempo de não trabalho, bem como incrementar os modos de trabalhar que moldam seu estilo de vida, o que condiz com a literatura afim (DAL ROSSO, 2008; GORZ, 2005; LAZZARATO e NEGRI, 2001;). Trata-se, de fato, de algo que não se reduz à quantificação da jornada de trabalho. Cinco minutos para responder e-mail são cinco minutos que mobilizam a vida, o que permite tomar como genuína a expressão "estou 24horas conectado às atividades da docência" (D8). Segunda: a avaliação do desempenho dos trabalhadores, nos atuais modos de gestão, levam em conta características como mobilização, identidade flexível, antecipação das necessidades dos clientes e resolução de problemas, além de agilidade nas respostas, entre outros (GAULEJAC, 2007; GORZ, 2005). Elas podem ser mobilizadas a qualquer tempo e lugar, no sentido de resolver as demandas produzidas e acolhidas na perspectiva da urgência. O elogio dos alunos/clientes à rapidez das respostas pode, portanto, estar relacionado com a aprovação pessoal pela instituição, a manutenção no emprego e a garantia do padrão de vida. Nesse sentido, práticas rotinizadas como a descrita a seguir por D6 configuram o trabalho como orientador de estilo de vida (GIDDENS, 2002). "Quando estou em casa, costumo consultar a internet pelo menos uma vez a cada hora. Parece-me que, se eu não fizer isso, vou estar perdendo alguma coisa" (D6).

Em que pese a invasão do tempo privado comprometer a vida (OLTRAMARI, GRISCI e WEBER, 2011; RUBERY, WARD, GRIMSHAW et al., 2005; WEBER e GRISCI, 2011; WEBSTER, 2004), o docente aceita as imposições do trabalho a fim de se destacar e ir mais longe na busca de um elevado padrão de vida (AUBERT, 2011; BAUMAN, 2010), para si ou para seus dependentes. Assim, suas práticas rotinizadas levam a confirmar que um estilo de vida pode ser "definido como um conjunto mais ou menos integrado de práticas que um indivíduo abraça, não só porque essas práticas preenchem necessidades utilitárias" (GIDDENS, 2002, p. 79), mas também porque dizem de sua intimidade. As práticas rotinizadas em relação àquilo que é dito ou feito sofrem ações avaliadoras em razão do modo de existência (DELEUZE, 1998), que implica uma estratégia existencial consumista (BAUMAN, 2008a). D17 é clara em relação ao que compartilha no facebook, o que permite observar sua compreensão da tecnologia como uma faca de dois gumes e um contingenciamento de liberdade a obrigar-lhe a uma reeducação contínua:

[...] apenas o que vai me ajudar na minha reputação profissional. É um negócio que é meu, mas não é. É público. A função de professor acaba lhe obrigando a fazer entalhes. Você tem que ser extremamente reservado. A parte relacional, tanto na internet como na vida real, ela é toda comedida, que não pode se expor. Você está num ambiente em que as pessoas lhe cobram equilíbrio emocional o tempo todo. Eu tento utilizar a internet a meu favor. Toda esta política de castração que eu estou me impondo, emocional, porque senão não sobrevivo no meu ambiente profissional. Infelizmente, é assim que o mundo funciona. A gente tem que fazer as adequações.

D9 consente que suas atividades profissionais ocupem "um pouco mais de tempo do que até as outras atividades, inclusive, lazer. Infelizmente, nós estamos vivendo num mundo, hoje, que é extremamente consumista, e a gente precisa estar atuante no mercado de trabalho para se atualizar e viver da maneira que a sociedade exige" (D9). O estilo de vida adotado correspondente à atualização e à atratividade, adquirindo, ele próprio, a característica de uma mercadoria de consumo. Consumir, diz Bauman (2008a, p. 75):

[...] significa investir na afiliação social de si próprio, o que, numa sociedade de consumidores, traduz-se em "vendabilidade": obter qualidades para as quais já existe uma demanda de mercado, ou reciclar as que já possui, transformando-as em mercadorias para as quais a demanda pode continuar sendo criada.

Para manter a "vendabilidade" (BAUMAN, 2008a), os docentes dedicam-se ao trabalho secundarizando outras instâncias da vida. Suas famílias pensam que eles trabalham muito, seus amigos não comentam porque se encontram no mesmo ritmo (D2). Devido à diminuição do convívio familiar, alguns exacerbam as 
colocações dizendo temer não ser reconhecidos pelos filhos (D14).Preocupam-se com o retorno financeiro (D12). Consideram a passagem do tempo muito rápida (D3). Gostariam de permanecer mais em casa sem trabalhar (D4) e de ter mais tempo para si (D6).

As práticas rotinizadas condizentes com a naturalização da colonização do tempo de vida se impõem como necessárias evidências de aptidão aos atuais modos de trabalhar intensificados pelas tecnologias da informação e comunicação. Impotente, o sujeito contempla uma possível ruptura das práticas rotinizadas, numa indicação da carência de perspectivas diferentes para o estilo de vida convertido em trabalho nos dias de hoje. "Nesta altura do campeonato, acho que não tem jeito. Tenho que continuar nesse ritmo" (D6). "Fazer o quê? É a vida" (D3).

Tudo isso remete, de algum modo e em algum grau, à invasão do tempo de trabalho no tempo de não trabalho. Destaca-se que, na pluralidade de escolhas possíveis, não se pode desconsiderar a inevitabilidade de um estilo de vida ou modo de existência relativo à estratégia existencial consumista a indicar que estilos de trabalho e estilo de vida retroalimentam-se, tampouco, a naturalidade com que isso passou a ser visto.

\section{Considerações Finais}

Este artigo buscou responder num contexto de trabalho imaterial, que estilo de vida decorre do uso do tempo permeado pelas tecnologias da informação e comunicação. As análises permitiram verificar que as tecnologias da informação e comunicação estão presentes no trabalho dos docentes horistas de instituições de ensino superior privadas, por meio de telefones celulares, notebooks com acesso à internet e outras tecnologias com acesso comunicacional. Seu uso se expande além do ambiente das instituições, correspondendo ao tempo de trabalho e também de não trabalho. Devido à mobilidade permitida, o acesso pode ser feito de diversos lugares, seja no trânsito, de casa, em restaurantes, supermercados etc. Desse modo, o docente está ao alcance da instituição e de suas demandas em qualquer hora e lugar. Ao julgar necessário consumir recursos tecnológicos que garantam sua apreciação como alguém atualizado e apto a responder com prontidão às demandas da instituição, o docente disponibiliza tempo e espaço de vida além dos termos contratuais de trabalho.

A partir do suporte teórico adotado - em especial Bauman (2008a), Deleuze (1998), Giddens (2002), Gorz (2005) e Lazzarato e Negri (2001) -, pode-se dizer que as tecnologias da informação e comunicação predispõem alterações nas práticas dos docentes horistas no que se refere ao tempo de trabalho e de não trabalho. Permitem tomar as práticas rotinizadas que evidenciam o estilo de vida dos docentes não como uma repetição monótona, mas como um modo de estar pessoalmente identificado com o trabalho, em clara disponibilidade e mobilização que resulta em respostas instantâneas, sem demora. As tecnologias da informação e comunicação (com suas características peculiares: a velocidade e a instantaneidade) se mostram como uma complementação à intensificação do trabalho, neste momento de evidente valorização do trabalho imaterial. Trata-se de um estilo de vida imposto aos docentes, os quais são instrumentalizados pelos modos de trabalhar.

Além disso, o uso das tecnologias da informação e comunicação expõe e intensifica o trabalho imaterial ao demandar que os sujeitos mobilizem seus conhecimentos, seus recursos e seu tempo pessoal no sentido de se apresentarem atualizados em relação a essas tecnologias. Desse modo, o estilo de vida resultante poderia ser chamado de estilo imposto de vida, pois os docentes o tomam na perspectiva de uma estratégia existencial consumista (BAUMAN, 2008a). Os estilos de trabalho produzem estilo de vida, podendo o trabalho ser tomado como componente fundamental das orientações do estilo de vida, de acordo com Giddens (2002).

Nos dias de hoje, a vida está sendo convertida em trabalho, tanto pela intensificação deste, como pelo prolongamento da jornada. $\mathrm{O}$ estilo de vida dos docentes horistas se mostrou decorrente e imbricado no exercício do trabalho imaterial e no uso das tecnologias da informação e comunicação que afetaram, sobremaneira, a experimentação do tempo. 
Mesmo contratado por tempo fracionado em horas, o trabalho dos docentes horistas exige-lhes disponibilidade e mobilização total para o desempenho das atividades laborais, requerendo o tempo integral da vida, o que se considera um achado importante deste estudo. Diante dos resultados, julgou-se pertinente não ter limitado o estudo à quantificação da jornada de trabalho, buscado uma compreensão qualitativa do tema. Diante da relevância da temática e dos resultados alcançados, sugere-se que futuros estudos contemplem perspectivas de resistência à realidade apresentada, bem como docentes com dedicação exclusiva ao exercício da docência.

\section{Referências}

ALVES, D. A. de. Tecnologias como mediadores das mudanças sociotécnicas no teletrabalho. Revista TOMO, n. 15, p. 142-65, jul./dez. 2009.

AUBERT, N. La société hyper moderne, l'individu hyper moderne: ruptures et contradictions. In: SEMINÁRIO DA AFAPP: L'ACCOMPAGNEMENT DES PROCESSUS DE CONSTRUCTION IDENTITAIRE - L'APPORT DE LA SOCIOLOGIE, 2011.2 Palestra. $\quad$ Disponível em: <http://www.afapp.org/images/docs/110530\%20Nicole\%20Aubert\%282\%29.pdf.>. Acesso em: 03 jul. 2012.

BAUMAN, Z. Globalização: as consequências humanas. Rio de Janeiro: Jorge Zahar, 1999.

Modernidade líquida. Rio de Janeiro: Jorge Zahar, 2001.

Vida para consumo: a transformação das pessoas em mercadoria. Rio de Janeiro: Jorge Zahar, 2008a.

A sociedade individualizada: vidas contadas e histórias vividas. Rio de Janeiro: Jorge Zahar, 2008b.

Capitalismo parasitário e outros temas contemporâneos. Rio de Janeiro: Jorge Zahar, 2010.

BOLTANSKI, L.; CHIAPELLO, E. O novo espírito do capitalismo. São Paulo: Martins Fontes, 2009.

BRASIL. Instituto Nacional de Estudos e Pesquisas Educacionais Anísio Teixeira. Censo da educação superior. Disponível em: <http://portal.inep.gov.br/web/censo-da-educacao-superior/>. Acesso em: 14 jun. 2012.

CASTELLS, M. A sociedade em rede. 8. ed. São Paulo: Paz e Terra, 2005.

; FERNÁNDEZ-ARDÈVOC, M.; QIU, J. L. et al. Comunicación móvil y sociedad, una perspectiva global. Disponível em <www.eumed.net/libros/2007c/312/>. Acesso em: 13 jan. 2011.

DAL ROSSO, S. Intensidade e imaterialidade do trabalho e saúde. Trabalho, Educação e Saúde, v. 4, n. 1, p. 65-91, 2006.

Mais trabalho! A intensificação do labor na sociedade contemporânea. São Paulo: Boitempo, 2008.

DELEUZE, G. Conversações: 1972-1990. Rio de Janeiro: Editora 34, 1998.

FREZZA, M.; GRISCI, C. L. I.; KESSLER, C. K. Tempo e espaço na contemporaneidade: uma análise a partir de uma revista popular de negócios. RAC, Curitiba, v. 13, n. 3, p. 487-503, jul./ago. 2009.

GAULEJAC, V. Gestão como doença social: ideologia, poder gerencialista e fragmentação social. Aparecida: Ideias \& Letras, 2007.

GIDDENS, A. Modernidade e identidade. Rio de Janeiro: Zahar, 2002.

GORZ, A. O imaterial. Conhecimento, valor e capital: São Paulo: Annablume, 2005. 
GRISCI, C. L. I. Trabalho imaterial, controle rizomático e subjetividade no novo paradigma tecnológico. RAEeletrônica, v. 7, n. 1, art. 4, jan./jun. 2008. Disponível em <http:// www.rae.com.br /eletronica/ index.cfm?FuseAction=Artigo \&ID=3424\&Secao=ARTIGOS\&Volume=7\&Numero=1\&Ano=2008>. Acesso em: 13 jan. 2011.

; SCALCO, P. D.; KRUTER, G. E. Dilemas pessoais no trabalho imaterial bancário. Psicologia \& Sociedade, v.

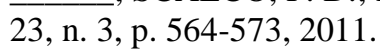

HAGUETE, T. M. F. Metodologias qualitativas na sociologia. Petrópolis: Vozes, 1995.

LAZZARATO, M.; NEGRI, A. Trabalho imaterial: formas de vida e produção da subjetividade. Rio de Janeiro: DP\&A, 2001.

MALENFANT, R.; FOUCHER, R. Work in a changing labour market and in changing parentsworkers expectations: the challenge of reconciling work time and time off. Retroscapes and futurescapes: temporal tensions in organizations. Palazzo d'Aumale, Terrasini (PA), Jun, 21-23, 2006. 1 CD-ROM.

MANSANO, S. R. V. Transformações da subjetividade no exercício do trabalho imaterial. Estudos e Pesquisas em Psicologia, UERJ, v. 9, n. 2, p. 512-524, 2009.

MINAYO, M. C. de S. (Org.). Pesquisa social: teoria, método e criatividade. Petrópolis: Vozes, 2001.

OLTRAMARI, A. P.; GRISCI, C. L. I.; WEBER, L. Carreira e relações familiares: dilemas de executivos bancários. Revista Mal-estar e Subjetividade, v. 11, n. 1, p. 101-133, mar. 2011.

PELBART, P. P. Vida capital: ensaios sobre biopolítica. São Paulo: Iluminuras, 2003.

POCHMANN, M. Crise internacional e perspectivas do trabalho. In: DAL ROSSO, S. (Org.). Trabalho na capital. Brasília, DF: Ministério do Trabalho e Emprego, 2011.

ROSENFIELD, C. L.; ALVES, D. A. de. Autonomia e trabalho informacional: o teletrabalho. DADOS - Revista de Ciências Sociais, Rio de Janeiro, v. 54, n. 1, p. 207-33, 2011.

RUBERY, J. et al. Working time, industrial relations and the employment relationship. Time \& Society, v. 14, n. 1, p. 89-111, mar. 2005.

WEBER, L.; GRISCI, C. L. I. Trabalho imaterial bancário, lazer e a vivência de dilemas pessoais contemporâneos. RAC, Curitiba, v. 15, n. 5, p. 897-917, set./out. 2011.

WEBSTER, J. Working and living in the European knowledge society: the policy implications of developments in working life and their effects on social relations. In: INFOWORK POLICY CONFERENCE, 2004, Brussels. Disponível em: <http://www.tcd.ie/ERC/past\%20symposia/infowork\%20symposia\%20docs/ Infowork \%20 Knowledge.pdf>. Acesso em: 20 nov. 2010. 